\title{
Dialogia
}

\section{Gêneros textuais, análise linguística e bullying: diálogos entre ensino de língua materna e cidadania}

\author{
Textual Genres, language analysis and bullying: a dialog between language pedagogy \\ and citizenship
}

Juliana Maria de Oliveira Moreira

Mestre em Letras - Universidade Federal de Juiz de Fora. Professora de Ensino Fundamental e Médio do Instituto Estadual de Educação de Juiz de Fora, MG - Brasil.

ju.ssva@gmail.com

Natália Sathler Sigiliano

Doutora em Linguística - Universidade Federal do Rio de Janeiro. Professora do mestrado profissional em Letras da Universidade Federal de Juiz de Fora, MG - Brasil. natalia.sigiliano@ufjf.edu.br

Resumo: Este trabalho discute o ensino-aprendizagem das classes de palavras adjetivo e advérbio, de forma reflexiva e pautada nos gêneros textuais, perpassado pelo tema transversal do bullying. A partir das perspectivas sociointeracionista de linguagem (KOCH; ELIAS, 2006), da análise linguística (GERALDI, 1984; MENDONÇA, 2006) e sob a metodologia da pesquisa-ação (THIOLENT, 1986; MORIN, 2004), relata e analisa resultados de intervenção realizada em aulas de língua portuguesa no $6^{\circ}$ ano com o objetivo de explicitar a relação entre as classes de palavras e os gêneros argumentativos e impulsionar discussões e reflexões sobre a prática de bullying. Os resultados da análise de dados revelaram que os alunos ganharam proficiência quanto ao uso mais formal dos adjetivos e dos advérbios em prol da argumentação, compreenderam melhor as características dos gêneros textuais envolvidos e mostraram-se pesquisadores e críticos de suas próprias realidades com relação à realidade do bullying na escola e às formas de abordá-lo.

Palavras-chave: Ensino de língua. Análise Linguística. Gêneros Textuais. Bullying.

\begin{abstract}
This paper discusses a reflexive teaching-learning approach to adjectives and adverbs, based on textual genres. Such an approach chooses bullying as a transversal thematic. Based on the social-interactionist approach to language (KOCH; ELIAS, 2006), on language analysis (GERALDI, 1984; MENDONÇA, 2006), and following the methodology of participatory action research (THIOLENT, 1986; MORIN, 2004), the paper reports on and analyzes the results of an intervention carried out in a 6th grade Portuguese Language class whose purpose was that of bringing to light the interrelation between parts of speech and argumentative genres, as well as to promote discussion on bullying. Results indicate that students gained proficiency in the use of adjectives and adverbs for argumentation, understood better the features of the textual genres involved and demonstrated critical thinking regarding their own environment, specially in what concerns bullying and ways to approach it.
\end{abstract}

Keywords: Language pedagogy. Analysis. Textual Genres. Bullying. 


\section{Desafios da escola e da sala de aula de língua portuguesa}

Há anos o ensino de língua portuguesa (LP) na educação básica vem passando por transformações, as quais surgem de um cenário de fortes indicações de que o texto passe a ser o centro da aula de língua materna. No entanto, em uma dificuldade de agir de forma distinta daquela recebida em sua formação, muitos professores ainda adotam práticas transmissivas. Junto a isso, nota-se a persistência da ideia de que fala, leitura e escrita só serão bem executadas se seus usos estiverem condicionados a um ensino de gramática pautado em identificações, classificações, formação e análise de frases soltas (ANTUNES, 2007), desconsiderando-se, portanto, a importância da contextualização de conteúdos e da reflexão sobre eles (MENDONÇA, 2006). Porém, documentos oficiais sobre o ensino de LP, como os parâmetros curriculares nacionais (BRASIL, 1997), e mesmo a mais recente Base Nacional Comum Curricular - BNCC (BRASIL, 2017), reiteram o fato de ser imprescindível que o processo de ensino-aprendizagem seja reflexivo e contextualizado, correlacionando gêneros textuais ao estudo dos fatos linguísticos para aquisição e desenvolvimento das habilidades de leitura, compreensão e produção de textos:

as abordagens linguística, metalinguística e reflexiva ocorrem sempre a favor da prática de linguagem que está em evidência nos eixos de leitura, escrita ou oralidade. Os conhecimentos sobre a língua, as demais semioses e a normapadrão não devem ser tomados como uma lista de conteúdos dissociados das práticas de linguagem, mas como propiciadores de reflexão a respeito do funcionamento da língua no contexto dessas práticas. (BRASIL, 2017, p.137)

Há que se destacar, ainda, que esse mesmo documento dá ênfase a dez competências que se associam à construção de conhecimentos e habilidades e à formação de atitudes e valores, perpassando todos os componentes curriculares, visando a uma formação contextualizada e ao protagonismo estudantil. Uma delas enfatiza a importância do exercício da empatia, da resolução de conflitos e do respeito a si e ao outro, com acolhimento e valorização da diversidade.

Ademais, no que concerne à temática escolhida para perpassar as ações, considera-se o fato de que, nos últimos anos, um tipo de violência sistematizada, que abarca todo tipo de agressões física e psicológica, intencional e repetitiva (BRASIL, 2015), típica do ambiente escolar e de outros setores da sociedade, especialmente aqueles em que há grande presença de crianças e adolescentes, tem sido motivo de muita atenção e de preocupação de professores, pais e pesquisadores, em razão de seu aumento significativo: trata-se do bullying. Para tanto, há uma legislação que reconhece a 
necessidade de se abordar o assunto, a fim de promover a cultura de paz para sua redução e consequente contenção.

Tudo isso aponta para um fato que é realidade na escola e nas aulas de LP e que não se pode ignorar ao se considerar a necessidade de se "construir uma escola voltada para a formação de cidadãos" (BRASIL, 1997): o trabalho com LP deve se dar de forma contextualizada ao uso e deve ser tomado como ferramenta eficaz para a formação do cidadão.

Nesse contexto, o presente artigo relata experiência de intervenção ${ }^{1}$ realizada em uma sala de aula de LP, a qual, tendo em vista necessidades reconhecidas pela professora-pesquisadora na escola em que a pesquisa-ação se inseriu, ensejou reflexões sobre os gêneros textuais e seus aspectos linguísticos, voltadas para o reconhecimento, análise e discussões da problemática do bullying na sala de aula e na instituição. A hipótese investigada ao longo do projeto de intervenção foi a de que o reconhecimento da importância que as classes adjetivo e advérbio desempenham na produção de gêneros do tipo argumentar, como resenha crítica e roda de conversa, podem auxiliar no desenvolvimento da capacidade dos alunos de se posicionarem criticamente nas mais diversas situações comunicativas. Reconhecida a proeminência da temática do bullying na instituição, criouse uma comunidade leitora relevante para as produções dos alunos.

Antes de se passar ao relato da intervenção, serão apresentados a seguir os pressupostos teóricos que embasaram a atuação em sala de aula. Na sequência, relatamos as etapas do projeto e, por fim, analisamos os dados resultantes da ação.

\section{Os gêneros textuais e a prática de análise linguística}

Como reflexo de mudanças na forma de encarar o objeto de análise da Linguística, os documentos que tratam sobre o ensino de LP passaram a inserir o trabalho com os gêneros textuais no centro da aula. Entretanto, tal indicação ainda não se revela como uma prática comum em sala de aula (ANTUNES, 2007) e nas formas de abordagem de conteúdos gramaticais em livros aprovados pelo Programa Nacional do Livro Didático (SIGILIANO \& SILVA, 2017). Isso revela que novas e velhas práticas, especialmente no que tange ao ensino de gramática, ainda convivem na aula de LP (MENDONÇA, 2006; BARBOSA, 2010).

Tendo em vista esse novo olhar que deve ser destinado ao ensino de gramática na escola, adotou-se para este trabalho a perspectiva da análise linguística (AL) em que "o trabalho com a gramática deixa de se basear em classificações descontextualizadas e volta-se para a exploração de 
recursos linguísticos colocados à disposição dos sujeitos para a construção dos sentidos" (BARBOSA, 2010, p. 158). Assim, a prática de AL não objetiva afastar a gramática das salas de aula, mas utilizá-la para enfatizar a maneira como ela pode ser um instrumento de ação pelo modo como os gêneros textuais se constituem, o que guia os alunos a práticas mais reflexivas, indutivas e investigativas sobre a própria língua.

Para que isso ocorra, Mendonça (2006, p.208) define a AL como:

\begin{abstract}
parte das práticas de letramento escolar, consistindo numa reflexão explícita e sistemática sobre a constituição e o funcionamento da linguagem nas dimensões sistêmica (ou gramatical), textual, discursiva e também normativa, com o objetivo de contribuir para o desenvolvimento de habilidades de leitura/escuta, de produção de textos orais e escritos e de análise e sistematização dos fenômenos linguísticos.
\end{abstract}

A mesma autora conclui que "a AL deve ser complementar às práticas de leitura e produção, uma vez que possibilitaria a reflexão consciente sobre os fenômenos textual-discursivos que perpassam os usos linguísticos nos momentos de ler/escutar ou de produzir textos" (MENDONÇA, 2006, p.225), reiterando a relevância da fusão desta prática com o trabalho com o uso da língua por meio da abordagem dos gêneros (MARCUSCHI, 2011) em atividades de leitura e produção de texto.

Como especificado na seção 1, a intervenção realizada em sala de aula teve como foco o trabalho com as classes de palavras que, conforme Pinilla (2014), deve ser abordado de forma a contemplar os critérios funcional, morfológico e semântico de modo articulado, intentando-se oferecer ao aluno um ensino de LP mais produtivo, que lhe permita avultar seus conhecimentos linguísticos e compreender a atuação de cada classe na produção de textos. Dessa forma, a intervenção sobre a qual este trabalho se refere destacou a proeminência de adjetivos e advérbios na construção de argumentos e na sustentação de opinião nos gêneros resenha crítica e roda de conversa, a fim de que o educando ampliasse suas capacidades argumentativas por meio do reconhecimento da importância do uso dessas classes de palavras nos gêneros supracitados.

Além disso, é importante ressaltar que a exploração dos gêneros textuais e dos aspectos linguísticos característicos deles contribuirão para o letramento escolar, bem como para o letramento social, considerando que o contato com gêneros característicos de esferas sociais distintas e a realização de atividades que priorizem a reflexão sobre os usos reais da língua desenvolvem as habilidades de leitura, compreensão e produção de textos e contribuem para uma participação mais plena dos educandos nas práticas sociais que se realizam no desempenho da linguagem verbal (PRETO-BAY, 2007). Nesse sentido, é fundamental que as aulas de LP 
ratifiquem os aspectos sociais da língua escrita, pois a linguagem é uma ferramenta social da interação.

\section{Metodologia}

Este trabalho foi pautado na metodologia da pesquisa-ação, que consiste em:

$$
\begin{aligned}
& \text { um tipo de pesquisa social com base empírica que é concebida e realizada em } \\
& \text { estreita associação com uma ação ou com a resolução de um problema } \\
& \text { coletivo e no qual os pesquisadores e os participantes representativos da } \\
& \text { situação ou do problema estão envolvidos de modo cooperativo ou } \\
& \text { participativo. (THIOLLENT, 1986, p. 15) }
\end{aligned}
$$

A pesquisa-ação permite que o pesquisador e seu lócus investigativo também sejam objetos da pesquisa, bem como o próprio objeto também possa desenvolver outros papéis neste processo investigativo. Nela, os participantes podem e devem interagir para que alcancem maior aprimoramento de suas capacidades e para que possam realizar uma troca de saberes e experiências

No caso da pesquisa-ação desenvolvida no contexto escolar, o protagonismo docente e o discente convergem para que o processo de ensino-aprendizagem seja renovado através de práticas que valorizem o exercício da reflexão acerca do objeto pesquisado e dos resultados obtidos em cada etapa, a fim de que outras ações possam ser desenvolvidas.

Neste artigo, serão apresentados resultados obtidos a partir da aplicação interventiva, focada na análise quantitativa comparativa de duas produções de resenhas críticas. Ademais, serão expostos resultados de análises realizadas a partir de uma entrevista estruturada, a qual foi aplicada pelos próprios alunos e versa sobre a ocorrência de bullying na instituição em que estudam.

O lócus de pesquisa foi uma turma de $6^{\circ}$ ano do Ensino Fundamental, de uma escola pública estadual de Juiz de Fora - MG, composta por 36 alunos matriculados. A pesquisa foi registrada e aprovada pelo Comitê de Ética em Pesquisa, sob o número 43927015.3.0000.5147. Todos os preceitos éticos para a pesquisa em Ciências Humanas foram devidamente observados e todos os dados dos participantes foram anonimizados.

A fim de que se tome conhecimento de todo o processo interventivo e dos resultados alcançados, serão relatadas as ações, seus impactos e resultados nas próximas seções. 


\section{Relato de intervenção: a ocorrência de bullying e o papel da aula de Língua Portuguesa}

É importante ressaltar que a intervenção a ser relatada é parte de um projeto desenvolvido no âmbito do mestrado profissional em Letras e que, neste artigo, apenas parte do projeto será enfocada.

Houve opção pelo ensino reflexivo das classes de palavras adjetivo e advérbio, nos gêneros resenha crítica e roda de conversa, o que se relaciona ao fato de os documentos oficiais, os currículos mínimos e os materiais didáticos focarem na necessidade de um trabalho com as classes de palavras nos anos iniciais do ensino fundamental II, sobretudo no $6^{\circ}$ ano. A escolha também está atrelada ao fato de a professora-pesquisadora ter verificado dificuldades quanto à compreensão de gêneros argumentativos e, consequentemente, das palavras e expressões responsáveis pela expressão de opinião nestes textos, quais sejam, adjetivos e advérbios.

Quanto à escolha da temática, esta também ocorreu em razão da necessidade apresentada pela turma, visto que, em momento anterior, os alunos relataram à docente situações em que presenciaram ou foram vítimas de bullying. Assim, foram desenvolvidas ações com intuito de fazer refletir sobre a necessidade de contenção dessa violência sistematizada.

A aplicação da intervenção iniciou-se com a apresentação do projeto à turma. A professorapesquisadora convidou os alunos à participação ativa, expondo que se tratava da aplicação de ações de ensino das classes de palavras adjetivo e advérbio em uma perspectiva reflexiva e pautada nos gêneros textuais. Ademais, destacou-se o fato de que todos seriam convidados a refletir, analisar e intervir em ações de bullying na escola, tendo em vista episódios de violência que vinham sendo enfrentados pelos alunos.

A fim de envolvê-los e, tendo em vista objetivos traçados para etapas seguintes, como o trabalho com filme e gênero resenha, desenvolveram-se atividades iniciais de sondagem do interesse dos alunos por cinema e do uso que faziam dos adjetivos e advérbios em suas produções textuais. Após a sondagem, foi realizado um trabalho com gêneros textuais motivadores - quiz sobre cinema, sinopse e comentário de site - com o intuito de iniciar o estudo reflexivo e contextualizado das classes lexicais na composição e criação de efeitos de sentido nos gêneros argumentativos, o que culminaria na produção de resenha crítica e na realização de rodas de conversa.

A seguir, a professora-pesquisadora promoveu uma roda de conversa para introduzir formalmente a temática da intervenção, cujo tema inicial abordava as sensações provocadas por 
determinados acontecimentos. A docente descreveu situações de prática de bullying e, ao passo que ela percebia o envolvimento dos educandos com o tema, este ganhava mais destaque.

Nessa roda de conversa, após os alunos efetuarem suas ponderações sobre as ocorrências de bullying das quais tinham conhecimento ou de que foram vítimas, a professora-pesquisadora destacou a importância do evento e do tema sobre o qual falavam e também chamou atenção para o fato de existirem leis que tratam especialmente desse tipo de violência, as quais os alunos desconheciam. Em seguida, alguns alunos se manifestaram para contar que a aluna recém-chegada na sala de aula foi vítima de bullying na instituição anterior, motivo pelo qual havia sido trocada de escola.

Após os relatos, a docente apresentou o filme "Extraordinário", dirigido por Stephen Chbosky, mostrando o livro que inspirou a produção, e comentou sobre os livros publicados a partir do sucesso conquistado pelo filme. Por fim, convidou os alunos para o assistirem. Nesse mesmo encontro, houve também um momento de contação de história, em que foi utilizado o livro "Somos todos extraordinários" (PALACIO, 2017), fato que contribuiu para despertar interesse pelo filme e pela leitura dos livros.

Em dia e horário combinados previamente, a turma foi direcionada para a sala de vídeo da instituição. Antes de a exibição ser iniciada, a professora recomendou que os alunos anotassem em seus cadernos observações sobre o filme, destacando o que mais lhes chamou a atenção, positiva e/ou negativamente porque, em outra ocasião, seria solicitada a eles a produção de uma resenha sobre a obra cinematográfica à qual assistiriam.

Os alunos demonstraram estima por "Extraordinário", reagindo, conforme o esperado, a cada situação vivida pelo protagonista. Em momento posterior à exibição do filme, a turma foi mobilizada para outra roda de conversa sobre a temática bullying e, dessa vez, com base no filme assistido, opinaram sobre ele, posicionando-se em relação à violência. Os alunos se organizaram em círculo e houve mediação constante da professora. Os educandos, na oportunidade, relacionaram a trama à própria realidade e relataram suas vivências.

Essa roda de conversa teve como objetivo qualificar os educandos para que respeitassem o turno de fala de seus interlocutores, e também para que soubessem posicionar-se no seu. $\mathrm{Na}$ ocasião, os alunos foram avaliados quanto ao uso dos adjetivos e advérbios na caracterização do filme e no posicionamento em relação a questões levantadas nele.

Em etapa posterior, como forma de retomada do filme assistido e de monitoramento quanto ao uso que vinha sendo feito dos adjetivos e dos advérbios no gênero, a docente iniciou o 
trabalho para a produção da resenha crítica ${ }^{2}$. Aspectos relevantes para a composição do gênero foram observados a partir da resenha de um outro filme. Durante a retomada, os alunos interagiram com a docente ao realizarem perguntas sobre a estrutura e o conteúdo do gênero. Após a retomada, os alunos iniciaram a produção textual de uma resenha crítica a ser publicada na página da instituição.

Entre a produção e a análise da produção textual, a docente propôs à classe uma pesquisa investigativa que mensurasse a ocorrência de bullying na instituição e oferecesse subsídios para outra roda de conversa em que os resultados pudessem direcionar uma reflexão sobre as ocorrências e o desenvolvimento de ações de contenção da prática.

Sob a mediação da professora-pesquisadora, os alunos foram divididos em 05 (cinco) grupos de trabalho e desenvolveram um instrumento de pesquisa para a aplicação de uma enquete nas turmas de $5^{\circ}$ a $9^{\circ}$ anos do ensino fundamental. Ao concluírem a aplicação da pesquisa, auxiliados pela professora de matemática da turma, os alunos iniciaram a compilação e levantamento dos dados obtidos.

A professora-pesquisadora organizou então outra roda de conversa para que pudessem discutir os resultados da pesquisa de campo e refletirem sobre as causas, os resultados e as possíveis ações de contenção da prática do bullying na instituição. Nesta roda de conversa, a professora também atuou como mediadora e incluiu a legislação sobre bullying, à qual os educandos tiveram acesso anteriormente, na conversa. Esta etapa representou um dos picos de participação ativa da classe, porque, além de ter consistido num evento escolar mais formal de oralidade, a professorapesquisadora reconheceu maior participação dos alunos e um grande interesse da parte deles em discutir o problema e apresentar soluções possíveis para sua resolução.

Concluída a roda de conversa, a professora retornou ao trabalho com o gênero resenha crítica a partir da seleção e apresentação aos alunos da produção de texto de um dos alunos, empreendendo análise conjunta que guiava as reflexões sobre o papel das classes de palavras proeminentes no gênero em foco, enfatizando mais precisamente a construção dos argumentos e a sustentação de opinião por meio dos adjetivos e dos advérbios.

Ao final dessa atividade, a docente ofereceu outras duas resenhas distintas como forma de realçar as características principais do gênero. Em seguida, entregou o texto aos alunos e solicitou que, a partir da primeira produção, reescrevessem as resenhas. Ao encerrar a reescrita, as produções finais também foram analisadas de acordo com os critérios estabelecidos para a produção inicial, com o propósito de estabelecer um comparativo entre ambas e avaliar os progressos obtidos da 
primeira para a segunda produção textual. Os resultados obtidos na análise e na avaliação das resenhas serão apresentados na próxima seção.

Finalizada a etapa das produções textuais, a docente iniciou a sistematização dos conhecimentos linguísticos sobre as classes adjetivo e advérbio, através de atividades introdutórias e de reflexão sobre o papel das referidas classes e de seus efeitos de sentido nos enunciados, desenvolvidas com base na releitura de trechos das resenhas disponibilizadas para leitura/estudo. Esta etapa foi de grande importância para a consolidação dos conhecimentos adquiridos, pois consistiu na conclusão das atividades de leitura, compreensão e produção de texto ao passo que tratava dos fatos linguísticos, sendo essas ações desenvolvidas sob o viés da AL.

Para concluir a intervenção, a professora-pesquisadora convidou a psicóloga para ministrar uma palestra sobre bullying para os alunos da turma e toda a comunidade escolar. Os resultados dos dados coletados pelos alunos foram disponibilizados para a palestrante com antecedência. No evento, foi possível divulgar os dados da pesquisa e interagir com a palestrante sobre a temática que, além de citar os males que a prática do bullying causa, também abordou os resultados da pesquisa realizada pelos educandos como forma de chamar a atenção para os casos ocorridos na escola e, principalmente, de conscientizar toda a comunidade escolar a não ser conivente com as ocorrências.

\section{Análise dos dados da intervenção}

Nesta seção, apresentar-se-ão os resultados obtidos na pesquisa realizada pelos alunos de $6^{\circ}$ ano sobre a ocorrência de bullying na instituição e os avanços alcançados no que diz respeito à produção do gênero resenha crítica sobre o filme "Extraordinário", que também aborda a temática.

\subsection{Análise da Pesquisa de Campo}

No que concerne ao trabalho de campo realizado pelos alunos do $6^{\circ}$ ano, responderam à pesquisa 68 alunos matriculados do $5^{\circ}$ ao $9^{\circ}$ anos da escola, no turno vespertino. O Quadro 1 traz as questões desenvolvidas pelos alunos e o percentual obtido por cada resposta. 
Quadro 1- Instrumento de pesquisa aplicado pelos alunos e respostas obtidas

\begin{tabular}{|l|l|l|}
\hline Afirmação & SIM & NÃO \\
\hline Já sofri bullying. & $63 \%$ & $37 \%$ \\
\hline Já testemunhei o bullying. & $75 \%$ & $25 \%$ \\
\hline Já testemunhei o bullying virtual. & $51 \%$ & $49 \%$ \\
\hline Já agredi ou humilhei alguém. & $20,5 \%$ & $79,5 \%$ \\
\hline Já tentei impedir uma situação de bullying. & $73,5 \%$ & $26,5 \%$ \\
\hline Já conversei com meus pais sobre o bullying. & $45,5 \%$ & $54,5 \%$ \\
\hline Já conversei com meus professores sobre o bullying. & $41 \%$ & $59 \%$ \\
\hline Já tive uma aula sobre bullying na escola. & $60 \%$ & $40 \%$ \\
\hline Acho que podemos deter o bullying na maioria dos casos. & $79,5 \%$ & $20,5 \%$ \\
\hline
\end{tabular}

Fonte: MOREIRA, 2018, p. 92

Os resultados foram discutidos com o intuito de promover reflexão sobre as ocorrências de bullying na instituição e sobre possíveis ações de contenção da prática. Ademais, ao mensurar a relevância do tema transversal para a comunidade, os alunos ganharam a percepção real do impacto que os textos por eles produzidos, acerca de um filme que aborda a mesma temática, teria para uma comunidade de leitores ampliada, extrapolando os limites da sala de aula e, portanto, cumprindo a função social do gênero textual alvo da intervenção. São apresentados a seguir os resultados e a análise deles empreendida pelos alunos em conversa sobre a enquete.

Os dados revelaram que $63 \%$ dos entrevistados afirmaram ter sofrido bullying e $75 \%$ presenciado a prática. Alguns alunos afirmaram acreditar que a ocorrência fosse ainda maior do que a registrada na pesquisa, e, segundo eles, mesmo tendo sido a enquete anônima, muitos poderiam não ter respondido sinceramente por receio de se expor. Segundo a visão deles, na maioria das vezes, a vítima teme que os ataques piorem, por isso, mente ou omite a verdade.

Em relação ao cyberbullying, constatou-se que 51\% dos participantes já o testemunharam. Os educandos relataram a existência de grupos criados em redes sociais, por alunos da instituição, com 
o objetivo de rechaçar e incitar o ódio entre alunos das séries anteriores. Outro grupo argumentou que o bullying virtual é mais comum porque sua descoberta é mais trabalhosa e complexa.

No tocante a agredir ou a humilhar alguém, o grupo mais atuante se mostrou incrédulo frente aos 79,5\% que negaram ter agredido ou humilhado colegas, porque, segundo eles, esse resultado não condiz com os 63\% que afirmaram sofrer bullying. Após a fala deste grupo, outro alegou que os próprios colegas da sala costumam formar grupos que se agridem verbalmente há algum tempo. Porém, até aquele momento, nenhuma providência havia sido tomada, nem por parte deles, nem por parte da instituição, que só tomou conhecimento dos fatos após o relato da docente. Ao final da fala dos alunos, a professora-pesquisadora conversou sobre o quanto essa revelação era preocupante e os fez refletir sobre a gravidade de seus atos e reconhecer a incoerência entre a discussão, a consciência que demonstravam quanto ao bullying e a postura que mantinham.

Quanto a impedir uma situação de prática de bullying, apenas 26,5\% afirmaram não as ter impedido. Alguns alunos, inclusive, afirmaram tentar evitar que colegas fossem agredidos fisicamente quando estudavam em outra instituição, relatando para a professora as ameaças que o colega sofria.

Sobre relatar para pais ou professores casos de bullying, 45,5\% e 41\% dos entrevistados, respectivamente, afirmaram falar sobre o assunto. Uma aluna considerou esses resultados incomuns, pois, segundo ela, o adolescente não costuma falar com os pais porque, frequentemente, são desacreditados por eles; muitos pensam que o filho está inventando histórias "para chamar sua atenção". Quanto a falar com professores, ela afirmou que, como o agressor e a vítima estão próximos no espaço escolar, esta se sente coagida a não contar absolutamente nada, sob a ameaça de sofrer agressões ainda piores. A docente explicou que silêncio da vítima fortalece a prática e que, por mais fragilizada que ela esteja, não deve enfrentar esses problemas sozinha.

No que tange ao fato de $60 \%$ dos entrevistados afirmarem ter tido uma aula sobre bullying, alguns educandos alegaram que, embora o resultado fosse aquele, o tema sempre é abordado. Entretanto, a correlação dessa resposta com a seguinte, levantou um dado que reforçou a relevância da intervenção proposta: ao comentar a última questão da enquete, sobre a possibilidade de se deter o bullying na maioria dos casos - em que 79,5\% dos entrevistados afirmaram ser possível prontamente uma aluna relatou que não acreditava que isso pudesse dar certo, pois, discutir o assunto não surtia grandes efeitos, sendo necessárias que haja ações mais concretas. Ao final de sua fala, sugeriu-se a criação de um grupo de apoio para ajudar os estudantes da instituição que sofreram ou estejam sofrendo bullying, e que, futuramente, esse grupo pudesse atender e integrar 
alunos de outras instituições. Muitos participantes apoiaram a iniciativa e se prontificaram a colaborar para o fortalecimento e a concretização do movimento.

Os resultados da pesquisa conduzida pelos próprios alunos apontam para a grande relevância do tema para a comunidade escolar, o que caracteriza uma situação ótima para a produção da resenha crítica sobre o filme "Extraordinário", que trata do tema. Os resultados obtidos com a análise da resenha são discutidos na sequência.

\subsection{Análise da Produção Textual}

No que concerne às produções textuais, foram analisados para fins diagnósticos aspectos estruturais como título, autoria, uso da $3^{\circ}$ pessoa, remissão ao produto resenhado - retomada anafórica -, identificação do autor da obra resenhada, recomendação ou não de consumo do produto resenhado e classificação. Também compuseram essa análise aspectos linguísticos como uso de adjetivos e advérbios, paragrafação, pontuação, registro (variedade linguística, ortografia e concordância), frases declarativas e clareza dos argumentos, selecionados para esta análise em consonância com o estudo desenvolvido nas etapas anteriores.

Dados os critérios, as produções eram consideradas adequadas quando atenderam aos requisitos presentes na tabulação; parcialmente adequadas quando se aproximaram para mais ou para menos dos parâmetros de análise, sinalizando algum nível de compreensão da composição do gênero; inadequadas quando não os contemplaram. Vejam-se os Gráficos 1, 2 e 3, que demonstram os resultados verificados na comparação da produção inicial com a produção final.

Como é possível notar, constataram-se avanços expressivos no uso de elementos como título, utilização mais adequada de pontuação e indicação de classificação, por exemplo, da produção inicial para a produção final, ao lado de aumentos consideráveis no que concerne ao uso de $3^{a}$ pessoa, remissão ao produto resenhado, identificação do autor da obra resenhada, uso de adjetivos, paragrafação e recomendação de consumo do produto resenhado. No que diz respeito aos dados considerados parcialmente adequados, confirmou-se relevante melhora nos quesitos uso de adjetivos, clareza dos argumentos, registro linguístico e paragrafação. Notou-se também a manutenção no uso de $3^{a}$ pessoa e dos advérbios para argumentação. É importante dizer que professora-pesquisadora apurou na produção inicial dos alunos uma forte tendência a utilizar as classes adjetivo e advérbio para narrar cenas do filme, ao invés de usá-las para argumentar sobre suas opiniões em relação ao filme. Porém, na produção final, boa parte desses casos foi adequada. 
Quanto às inadequações, observa-se queda nas referentes aos aspectos título, uso da $3^{\text {a }}$ pessoa, remissão à obra resenhada, uso de adjetivos, clareza dos argumentos e paragrafação. Embora esta seja uma representação quantitativa, trata-se de uma análise qualitativa de avanços alcançados pelos discentes representada numericamente para fins comprobatórios.

Gráfico 1- Produções consideradas adequadas

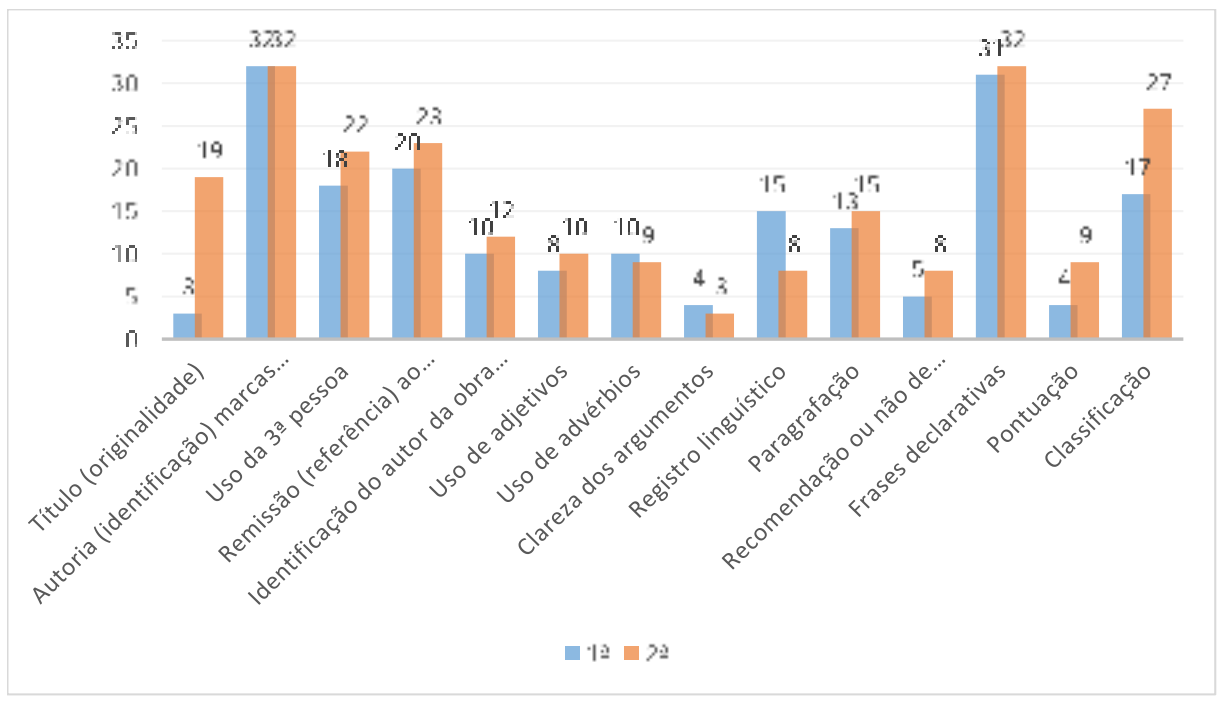

Fonte: MOREIRA, 2018, p. 118

Gráfico 2 - produções parcialmente adequadas

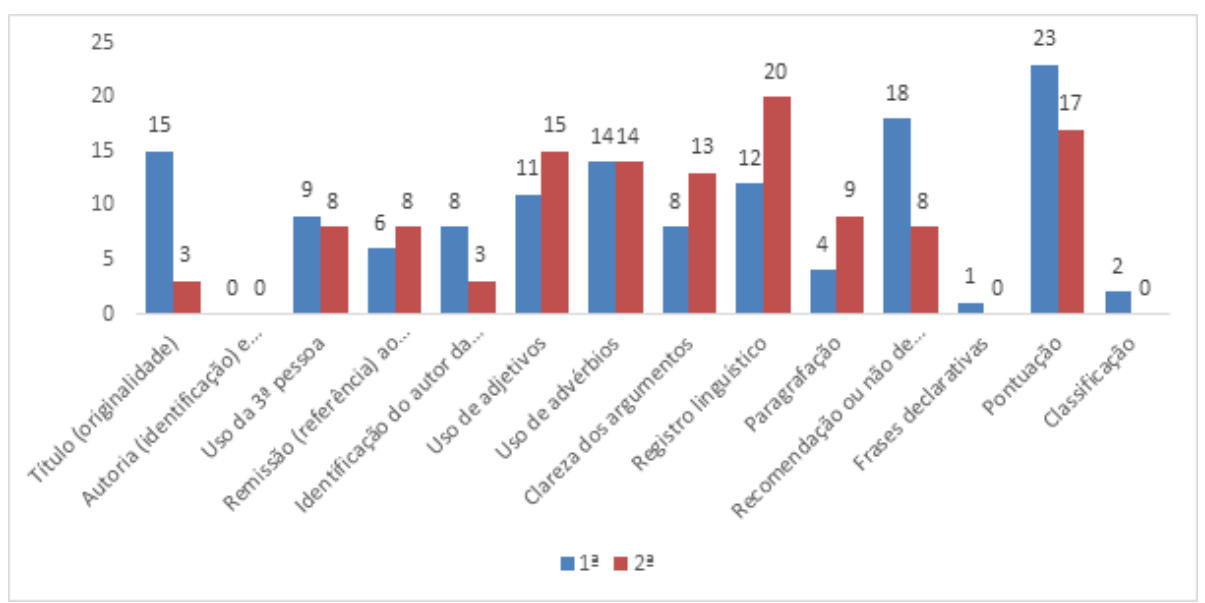

Fonte: MOREIRA, 2018, p. 119 
Gráfico 3 - Produções inadequadas

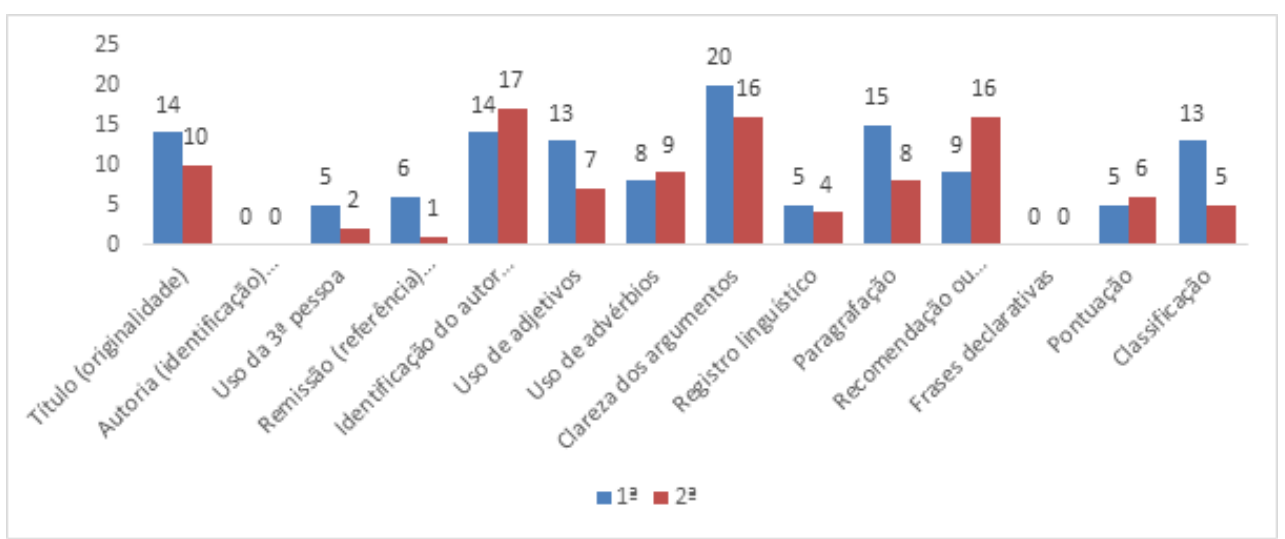

Fonte: MOREIRA, 2018, p. 119

\section{Considerações Finais}

A intervenção relatada neste artigo possibilitou a realização de um trabalho reflexivo e muito impactante para a comunidade escolar, dada a relevância da temática transversal. Os objetivos primordiais consistiram em explorar o protagonismo discente e em guiar o aluno à percepção da função argumentativa das classes de palavras advérbio e adjetivo nos gêneros resenha crítica e a roda de conversa, desenvolvendo e ampliando suas capacidades de leitura, compreensão e reconhecimento de ponto de vista nos referidos gêneros. Esses objetivos estão atrelados à hipótese de que, através do trabalho com a gramática contextualizada e sob o viés da AL, os educandos estariam capacitados a usar a língua de forma ainda mais autônoma nos contextos escolar e social. No que concerne à temática, buscou-se que repudiassem a prática do bullying e que fossem capazes de realizar alguma atitude responsiva frente à sua possível ocorrência.

Ao final das ações, constatou-se que os educandos participaram ativamente de todos os processos desta intervenção, demonstrando maior autonomia linguística ao serem expostos a situações, orais ou escritas, em que deveriam argumentar e justificar seu ponto de vista. Quanto ao uso de adjetivo e advérbio enquanto elementos argumentativos, observou-se um discreto aumento na utilização dessas classes morfológicas. No que concerne à temática desta intervenção, os discentes demonstraram estar conscientizados sobre os males provocados pela prática do bullying através de suas atitudes responsivas, verificadas durante a realização da pesquisa de campo e das rodas de conversa, que culminou na proposta de criação de um grupo de apoio aos alunos vítimas desse tipo de violência. 


\section{Referências}

ANTUNES, I. Muito além da gramática: por um ensino de línguas sem pedras no caminho. São Paulo: Parábola Editorial, 2007.

BARBOSA, J. P. Análise e reflexão sobre a lingua e as linguagens: ferramentas para os letramentos. In: RANGEL, E. O. \& ROJO, R. H. (coord.). Lingua Portuguesa: ensino fundamental. Brasília: Ministério da Educação, Secretaria de Educação Básica, 2010, p. 155-82

BRASIL, Ministério da Educação. Base Nacional Curricular Comum. Disponível em: $<$ http://basenacionalcomum.mec.gov.br/images/BNCC 20dez site.pdf $>$. Acesso em: 10 jan. 2018

BRASIL, Ministério da Educação. Parâmetros Curriculares Nacionais - Ensino fundamental - Língua Portuguesa. Brasília: SEF/MEC, 1998.

BRASIL. Lei no 13.185, de 06 de novembro de 2015. Institui o Programa de Combate à Intimidação Sistemática (Bullying). Disponível em:

< http://www.planalto.gov.br/ccivil 03/ ato2015-2018/2015/lei/113185.htm>. Acesso em: 06 abr. 2018.

MARCUSCHI, L. A. Gêneros textuais: configuração, dinamicidade e circulação. In:

KARWOSKI, A. M.; GAYDECZKA, B. \& BRITO, K. S. Gêneros textuais: reflexões e ensino. 4 ed. São Paulo: Parábola Editorial, 2011, p. 17-32

MENDONÇA, M.. Análise linguística no ensino médio: um novo olhar, um outro objeto. In: BUNZEN, C. \& MENDONÇA, M. (orgs.). Português no ensino médio e formação de professores. São Paulo: Parábola Editorial, 2006, p. 199-226

MOREIRA, Juliana Maria de Oliveira. Gêneros pautando um ensino reflexivo do adjetivo e do advérbio: discussões sobre bullying e cinema em um novo contexto escolar. Dissertação (Mestrado em Letras) Faculdade de Letras, Universidade Federal de Juiz de Fora. Juiz de Fora, 2018, 196 p.

PINILLA, M. da Aparecida de. Classes de palavras. In: VIEIRA, Silvia Rodrigues; BRANDÃO, S. F. (orgs.). Ensino de gramática: descrição e uso. 2 ed. São Paulo: Contexto, 2014. p. 169-83

PRETO-BAY, A. M. R. Acesso social, práticas educativas e mudanças teórico-pedagógicas ligadas ao género textual. In: SCHOLZE, Lia; RÖSING, Tania M. K. (orgs.). Teorias e práticas de letramento. Brasília: Instituto Nacional de Estudos e Pesquisas Educacionais Anísio Teixeira, 2007. p. 17-36

SIGILIANO, N. S.; SILVA, W. Res. Diagnóstico de propostas de análise linguística em livros didáticos aprovados em programa oficial. In: MAGALHÃES, Tânia Guedes; GARCIA-REIS, Andreia Rezende; FERREIRA, Helena Maria (orgs.). Concepção discursiva da linguagem: ensino e formação docente. Campinas: Pontes Editores, 2017. p. 19-42

THIOLLENT, M. Metodologia da pesquisa-ação. 2 ed. São Paulo: Cortez, 1986. 


\title{
Dialogia
}

\begin{abstract}
${ }^{1}$ A palavra "intervenção" será empregada, neste texto, para se referir a um momento de aplicação por parte da professora-pesquisadora de aulas planejadas previamente.

${ }^{2}$ Em momento distinto, o gênero já havia sido analisado e interpretado, de modo que, para a produção textual, as análises foram retomadas a partir de conhecimentos prévios adquiridos nesta intervenção.
\end{abstract}

Recebido em: 15 abr. 2019 / Aprovado em: 25 jun. 2019

\section{Cite como}

MOREIRA, Juliana Maria de Oliveira; SIGILIANO, Natália Sathler. Gêneros textuais, análise linguística e bullying: diálogos entre ensino de língua materna e cidadania. Dialogia, São Paulo, n. 32, p. 120-135, maio/ago. 2019. Disponível em: https://doi.org/10.5585/Dialogia.n32.13628. 